\title{
Rendimento Académico: Influência do Autoconceito e do Ambiente de Sala de Aula
}

\author{
Maria Olímpia Almeida de Paiva ${ }^{1}$ \\ Abílio Afonso Lourenço \\ Escola Secundária Alexandre Herculano - Porto - Portugal
}

\begin{abstract}
RESUMO - Este trabalho tem como objectivo verificar se o autoconceito dos alunos, avaliado pela escala PHCSCS-2, e o ambiente da sala de aula, analisado pela escala APSA, são relevantes na explicação do rendimento académico. Participaram 217 alunos (112 rapazes e 105 raparigas) do $3 .^{\circ}$ Ciclo do Ensino Básico, de uma escola pública do norte de Portugal. Para o tratamento dos dados recorreu-se a modelos de equações estruturais. Constatou-se que o autoconceito e o ambiente de sala de aula têm um impacto positivo e significativo no rendimento académico dos alunos (Língua Portuguesa e Matemática), bem como o autoconceito afecta positivamente esse mesmo ambiente. São discutidas implicações educativas dos resultados.
\end{abstract}

Palavras-Chave: Autoconceito, ambiente de sala de aula, rendimento académico, modelos de equações estruturais.

\section{Academic Achievement: Influence of Self-concept and Classroom Environment}

\begin{abstract}
The objective of this study is verify whether the self-concept of students, measured by the scale PHCSCS-2, and the classroom environment, assessed with the APSA scale, are relevant factors explaining academic achievement. 217 students (112 males and 105 females) of a public school in north of Portugal participated in this study. Structural Equation Modeling was used to analyze the data. The results indicated that self-concept and classroom environment have a significant and positive impact on the language and mathematics achievement of the students and that self-concept positively affects the classroom environment. The educational implications of the results are discussed.
\end{abstract}

Keywords: Self-concept, classroom environment, academic achievement, structural equation modeling.

Uma das preocupações actuais das comunidades educativas está centrada na problemática do fracasso escolar e do correspondente abandono precoce. Um dos caminhos para superar esse fracasso escolar passa pela criação de ambientes de sala de aula, através dos quais os alunos aumentem a sua implicação na aprendizagem, desenvolvam um papel de agentes activos e possam evidenciar sinais de informação indispensável para explicar a causa ou o desenvolvimento dos problemas educacionais, adaptativos, entre outros. Assim, como refere Simões (2001), o espaço de sala de aula fornece dados importantes para analisar o autoconceito, onde a escola tem, nos dias de hoje, ocupado uma função importante na vida afectiva dos jovens ao mesmo tempo que facilita elementos para eles se auto-conhecerem.

Partindo do princípio que o autoconceito se apresenta como um aspecto essencial da personalidade de cada indivíduo, regulando as suas acções de forma diferente conforme seja positivo ou negativo, torna-se importante entender como se manifesta diferencialmente em adolescentes, na medida em que poderá permitir uma melhor compreensão de como estes se ajustam aos diversos contextos de vida em que interagem (Paiva, 2004). O autoconceito é um construto que tem causado um grande interesse por parte dos investigadores, onde a literatura revela uma panóplia de definições das quais destacaremos a de Bandura (1986) que o definiu como

1 Endereço para correspondência: Rua Santos Pousada, 384, 2A H11 4000-478. Porto -Portugal. Telefone: 00351.220176714; Telemóvel: 00351.917135204 Email: cipe.esah.investigar@gmail.com "uma visão composta de um indivíduo que é formada através da experiência directa e avaliações adoptadas de outras pessoas significativas" (p. 409). Este conceito de si mesmo possui, também, um aspecto avaliativo, que possibilita que o sujeito se auto-avalie, aferindo quais os comportamentos mais ajustados, e permite retirar daí informação relevante para novas situações.

Se no passado o (in)sucesso escolar era atribuído essencialmente a factores de ordem psicobiológica, sociológica e pedagógica, actualmente, a investigação parece conceder uma importância crescente a variáveis afectivo-motivacionais (Giavoni \& Tamayo, 2003; Leitão, 2008; Lourenço \& Paiva, 2004), como o autoconceito, que, ao fazer parte do processo de aprendizagem, actua ao nível da motivação dos alunos, influenciando, por isso, o desempenho académico dos mesmos (Inglez de Souza \& Ferreira de Brito, 2008).

Assim, para se entender esta problemática é fundamental ter uma perspectiva holística, especificamente através da consideração de factores pessoais, interpessoais e institucionais. O estudo do autoconceito escolar tem sido destacado considerando a importância conferida a esse construto na dinâmica das relações que ocorrem no contexto escolar. Desde o final da década de 70 do século XX, se admite que um dos factores centrais do rendimento académico é o autoconceito, determinado no contexto educativo pela qualidade das relações estabelecidas entre o professor e o aluno (Burns, 1979; Byrne, 1986). Os estudos desenvolvidos tendo como objectivo a procura das relações entre o autoconceito e o 
desempenho académico têm sofrido um incremento ao longo dos anos e os resultados dessas investigações aludem para uma persistente e significativa relação entre as duas variáveis (Inglez de Souza \& Ferreira de Brito, 2008; Köller, Daniels, Schnabel \& Baumert, 2000), apesar das relações entre o autoconceito geral e o sucesso escolar serem relativamente baixas (Byrne, 1986; Marsh \& Craven, 1997; Marsh, Craven \& Debus, 1998; Paiva, 2009).

De forma idêntica, a sala de aula tem sido objecto de um grande número de pesquisas realizadas por diversas disciplinas (Cirino, Eiterer \& Guimarães, 2004; Liparini \& Munford, 2005). Dentre as várias possibilidades de abordagem da sala de aula, a análise do ambiente de aprendizagem tem sido uma das opções de trabalho no campo educacional. $\mathrm{O}$ interesse em investigações abarcando a avaliação e o estudo da percepção de aspectos do ambiente de aprendizagem da sala de aula tornaram esta área como um próspero campo de estudo.

Quanto à terminologia usada nas Ciências Humanas e Sociais, o termo ambiente de sala de aula comporta uma diversidade de significados. Frequentemente, o conceito ambiente de aprendizagem tem sido utilizado para fazer alusão, por exemplo, ao ambiente psicossocial da sala de aula, à gestão da disciplina e das normas da sala de aula e à aquisição de capacidades sociais. Além disso, qualquer investigador ao estudar este tema poderá encontrar outras expressões que se referem ao mesmo objecto de estudo, nomeadamente o ambiente de aprendizagem da sala de aula, o ambiente social da sala de aula, o clima da sala de aula, o clima social da sala de aula e o ambiente da sala de aula. De realçar que essa diversidade de formas pode ser encontrada, por vezes, dentro de um mesmo texto. A este respeito, Walker (2004) argumenta que a literatura especializada encerra distintas terminologias quando se refere ao conceito de ambiente, citando que, no seu trabalho, esse conceito diz respeito unicamente ao ambiente psicossocial. O autor propõe, ainda, uma distinção quando nos diz que a expressão ambiente psicossocial é utilizada quando faz referência ao ambiente de uma forma geral, e o termo ambiente de aprendizagem, quando este se relaciona com o ambiente psicossocial na educação.

Relativamente ao início da investigação acerca do ambiente da sala de aula, Walker (2004) afirma que Walberg e Moos começaram a examinar o ambiente psicossocial e a sua influência nos resultados académicos dos alunos nas décadas 60 e 70 do século XX, constituindo-se esta como a tradição de pesquisa mais forte (Fraser, 2002). É frequente descortinar na literatura da área ligações entre variáveis do ambiente de aprendizagem e o (in)sucesso dos alunos, tanto no campo cognitivo quanto no afectivo, podendo-se considerar como resultados cognitivos as notas alcançadas pelos alunos (Cook, Gresham, Kern, Barreras, Thornton \& Crews, 2008). Quando se ponderam os resultados afectivos dos alunos a questão torna-se mais complexa. Definir o termo afectivo não é uma tarefa fácil, porque este pode suscitar uma variedade de significados. Neste campo de investigação, a expressão aparece ligada, essencialmente, ao estudo dos comportamentos e das atitudes dos alunos. Nesse sentido, as pesquisas acerca do afecto dos alunos são referidas como pesquisas atitudinais.
Os autores que trabalham nessa linha de investigação intentam esforços no sentido de não dar excessiva importância ao campo cognitivo e dar mais atenção aos resultados do lado afectivo. Procuram, para além disso, mostrar evidências de que a percepção do ambiente de aprendizagem da sala de aula pode ter impacto no sucesso escolar dos alunos. As investigações sobre o ambiente de aprendizagem indicam benefícios múltiplos na utilização das crenças dos alunos como um indicador da qualidade do ambiente da sala de aula (Formiga, 2004).

Contudo, alguns autores asseguram que essas associações já estão suficientemente demonstradas. Fraser (2002), por exemplo, faz referência a um conjunto de investigações que testemunha esse tipo de ligação utilizando uma diversidade de medidas de resultados cognitivos e afectivos, como ainda foram usados múltiplos instrumentos de avaliação do ambiente de aprendizagem da sala de aula em distintos países e níveis de ensino.

Da revisão da literatura fica a ideia de que é possível estudar o clima de maneira única em cada escola, sem utilizar características definidas antecipadamente, fazendo destacar as características mais evidentes como as que são apreendidas pelos membros da organização. Esta abordagem considera o clima fruto da personalidade das pessoas, das suas interacções no sistema psicossocial, dos seus processos de influência, convicções, expectativas e valores. Por conseguinte, as representações do clima organizacional tem como resultados as reacções afectivas e os comportamentos dos membros da organização.

Investigações várias, quer transversais quer longitudinais têm destacado que as percepções positivas dos alunos acerca do clima da sala de aula aparecem associadas a um maior autoconceito e adaptação académica, bem como com menores problemas comportamentais e emocionais (Veiga, 2001).

Ainda sobre os construtos autoconceito e ambiente de sala de aula, são escassos os estudos que relacionam, directamente, estas duas variáveis. Num estudo de Parker (2009), realizado com 125 alunos, um dos objectivos da investigação foi analisar o autoconceito dos adolescentes e as percepções do ambiente de sala de aula durante a transição entre dois níveis escolares $\left(5 .^{\circ}\right.$ e $6 .^{\circ}$ ano). Os resultados sugerem que não existem diferenças nestes dois contrutos antes e após a transição. Porém, com o passar do tempo, foi possível observar um incremento do autoconceito dos alunos, sendo os resultados das percepções do ambiente de sala de aula inconclusivos. Sobre esta variável, um estudo de Oldfather e McLaughlin (1993) constatou um decréscimo na percepção do ambiente de sala de aula após a transição nestes mesmos níveis de ensino.

Os factores previamente explanados são capazes de explicar o fenómeno do rendimento académico, tido presentemente como uma das grandes inquietações, não só no âmbito educacional, como também no social e, ainda, no individual. Mas esse problema faz parte de um amplo contexto, devendo-se ponderar todas as possíveis variáveis envolvidas neste processo. Algumas dessas variáveis são objecto de estudo deste trabalho.

A opção por este tema de investigação justifica-se pela necessidade de compreender mais pormenorizadamente 
o processo de ensino/aprendizagem, com a finalidade de melhorar os resultados de aprendizagem dos alunos. Como professores, ambicionamos perceber de uma forma mais clara de que modo o autoconceito dos alunos e o ambiente de sala de aula podem influenciar a avaliação escolar. Também se pretende analisar de que modo algumas variáveis sócio-demográficas estão relacionadas com o autoconceito dos alunos, bem como a relação deste com o ambiente de sala de aula.

Os construtos em estudo revelam-se, assim, de uma importância social e científica. O autoconceito quando relacionado com o sucesso académico, poderá ser considerado como a variável motivacional mais importante para potenciar a adaptação aos diferentes níveis de ensino. Alunos e professores devem desenvolver competências em conjunto, cooperativa e competitivamente, procurando proporcionar melhores formas e prazer para o acto de aprender e ensinar (Edinger, 2000), e, especialmente, interagir, favorecendo competências sociais indispensáveis para conviver com as diferenças tanto étnicas quanto intelectuais.

As relações interpessoais proporcionam experiências conjuntas e, para que todos os intervenientes possam ser beneficiados no âmbito motivacional, é essencial que se facultem espaços em que cada um possa participar de uma forma activa, apresentando os seus saberes individuais a favor do grupo e que estejam receptivos a tudo aquilo que os outros lhe possam oferecer, nomeadamente a troca de conhecimentos e sentimentos. Huertas (2000) refere que “(...) para qualquer aprendizagem é preciso que o meio seja emocionalmente adequado. Ou seja, um espaço de relações interpessoais onde predominem a aceitação e respeito mútuo" (p.138). O autor refere a importância de se criar ambientes em que os alunos se sintam à vontade e seguros para relatarem as suas convicções e onde possam percepcionar sensações de efectivo progresso na sua aprendizagem e de satisfação pelo trabalho que exercem. Num ambiente de cumplicidade, o aluno facilmente coloca dúvidas, criando-se assim as condições para uma melhor aprendizagem. Desta forma, os ambientes educacionais podem ser considerados como contextos psicossociológicos condicionantes da aprendizagem (Fraser, 1986). Deste modo, as investigações sobre o ambiente de aprendizagem indicam benefícios múltiplos na utilização das crenças dos alunos como um indicador da qualidade do ambiente da sala de aula (Formiga, 2004; Veiga, 2001).

Reclama-se, assim, que o professor diversifique as estratégias, proponha desafios, compare, dirija e esteja atento à diversidade dos alunos, o que significa estabelecer uma interacção directa com os mesmos. O professor é detentor de um conjunto de funções nessas relações interactivas, nomeadamente: ajudar os alunos a dar significado e importância ao que fazem, comunicando objectivos, levando-os a compreender os processos e o que se espera deles; criar um ambiente de sala de aula que facilite o autoconceito dos alunos; estabelecer canais de comunicação entre professor/ aluno e aluno/aluno; potenciar a autonomia, permitindo a metacognição; e avaliar o aluno tendo em consideração a sua capacidade e esforço.

\section{Método}

\section{Participantes}

Para os modelos de equações estruturais, foi utilizada uma amostra de 217 alunos do $3 .^{\circ}$ Ciclo do Ensino Básico (CEB), distribuídos por 15 turmas. Esta amostra foi recolhida numa escola secundária com $3 .^{\circ}$ ciclo, do centro do Porto-Portugal, de perfil tipicamente urbano. A investigação foi centrada unicamente nesta escola, onde desenvolvemos a nossa actividade docente e com isso pretendermos compreender mais pormenorizadamente o processo de ensino/aprendizagem, tendo como finalidade melhorar os resultados de aprendizagem dos alunos. Seguidamente, passaremos a descrever a nossa população em função das seguintes variáveis: sexo, idade, ano de escolaridade, número de reprovações, metas escolares, horas de estudo e classificação obtida, no final do $2 .^{\circ}$ período, às disciplinas de Língua Portuguesa e Matemática.

Relativamente à variável sexo, dos 217 sujeitos, 112 $(51,6 \%)$ são do sexo masculino, e $105(48,4 \%)$ pertencem ao feminino. No que se refere ao ano de escolaridade, poderemos constatar que $46(21,2 \%)$ alunos frequentam o $7 .^{\circ}$ ano, 84 $(38,7 \%)$ o $8 .^{\circ}$ e $87(40,1 \%)$ o $9 .^{\circ}$ ano de escolaridade. Em relação à variável idade, os alunos da amostra distribuem-se entre os 12 e os 20 anos $(\mathrm{M}=15,2 ; \mathrm{DP}=1,73)$, existindo dois alunos com 19 anos e quatro com 20 . Verifica-se que os alunos do $7 .^{\circ}$ ano de escolaridade apresentam uma média etária de 13,3 anos $(\mathrm{DP}=0,89)$, os do $8 .^{\circ} 15,5(\mathrm{DP}=1,65)$ e os do $9 .^{\circ}$ uma média de $16,0(\mathrm{DP}=1,33)$. Como se pode constatar, nos três anos escolares, a maioria dos alunos apresenta idades um pouco desajustadas ao ano de escolaridade que frequenta. No $7 .^{\circ}$ ano existem 27 alunas com uma média de idades de 13,0 anos $(\mathrm{DP}=0,78)$ e 19 rapazes com uma média etária de $13,7(\mathrm{DP}=0,89)$. Relativamente ao $8 .^{\circ}$ ano fazem parte da amostra 34 raparigas com uma média de idades de 15,5 $(\mathrm{DP}=1,83)$ e 50 elementos do sexo masculino com uma idade média de 15,4 anos $(\mathrm{DP}=1,54)$. No que concerne ao $9 .^{\circ}$ ano de escolaridade, 43 alunos são do sexo masculino, com uma média de idades de 15,9 anos $(\mathrm{DP}=1,32)$ e 44 são raparigas, com uma média de idades de 16,1 ( $\mathrm{DP}=1,35)$.

Seguidamente, apresentamos uma distribuição conjunta dos alunos segundo o ano de escolaridade, o sexo, horas de estudo e metas escolares (cf. Tabelas 1 e 2). Da Tabela 1 verifica-se que só no $7 .^{\circ}$ ano de escolaridade é que os rapazes reprovam mais do que as raparigas. É de realçar que as raparigas do 8..$^{\circ}$ ano são as que mais reprovam. Quanto às horas de estudo, em todos os anos de escolaridade são os rapazes que apresentam melhores médias, sendo o $8 .^{\circ}$ ano o que apresenta uma média inferior. É de realçar que, em todos os anos de escolaridade, esse investimento por parte dos rapazes é mais do que o dobro das raparigas. Relativamente ao tempo de estudo das alunas este vai aumentando ao longo dos anos de escolaridade. No que diz respeito às notas de Língua Portuguesa e Matemática, os rapazes obtêm sempre melhores resultados do que as raparigas, com excepção, no 8..$^{\circ}$ ano, à disciplina de Língua Portuguesa. Na disciplina de Matemática os alunos nunca conseguiram atingir uma média igual ou superior a três, no entanto na disciplina de 
Tabela 1. Distribuição dos mínimos, máximos, médias e desvios-padrão do n. ${ }^{\circ}$ de reprovações, horas de estudo e notas de Língua Portuguesa e Matemática, em função do ano de estudo e sexo

\begin{tabular}{|c|c|c|c|c|c|c|c|c|c|c|c|c|c|c|}
\hline \multirow{3}{*}{ Variáveis } & \multicolumn{7}{|c|}{$7 .^{\circ}$ ano } & \multirow{2}{*}{\multicolumn{2}{|c|}{$\begin{array}{c}8 .^{\circ} \text { ano } \\
\text { fem. }\end{array}$}} & \multicolumn{5}{|c|}{$9 .^{\circ}$ ano } \\
\hline & \multicolumn{3}{|c|}{ masc. } & \multicolumn{2}{|c|}{ fem. } & \multicolumn{2}{|c|}{ masc. } & & & \multicolumn{2}{|c|}{ masc. } & \multicolumn{2}{|c|}{ fem. } & \multirow[b]{2}{*}{ DP } \\
\hline & Min & Máx & $\mathrm{M}$ & DP & $\mathrm{M}$ & DP & M & $\mathrm{DP}$ & $\mathrm{M}$ & DP & M & DP & M & \\
\hline N. ${ }^{\circ}$ Reprovações & 0 & 5 & 1,54 & 1,19 & 0,70 & 0,78 & 1,86 & 1,31 & 2,15 & 1,67 & 1,42 & 1,05 & 1,84 & 1,18 \\
\hline Horas de Estudo & 0 & 9 & 3,31 & 2,73 & 0,81 & 1,67 & 2,78 & 2,55 & 1,15 & 1,74 & 4,09 & 2,83 & 2,02 & 1,71 \\
\hline $\begin{array}{l}\text { Nota de } \\
\text { Língua Portuguesa }\end{array}$ & 1 & 5 & 2,84 & 0,77 & 2,41 & 0,84 & 2,84 & 0,65 & 2,91 & 0,79 & 3,05 & 0,82 & 2,95 & 0,71 \\
\hline Nota de Matemática & 1 & 5 & 2,70 & 1,00 & 2,19 & 0,68 & 2,90 & 0,89 & 2,88 & 1,07 & 2,70 & 1,04 & 2,66 & 0,83 \\
\hline
\end{tabular}

Tabela 2. Distribuição dos alunos segundo o ano de escolaridade, sexo e metas escolares

\begin{tabular}{clllcccc}
\hline \multirow{2}{*}{ Ano } & \multirow{2}{*}{ Sexo } & \multicolumn{7}{c}{ Metas Escolares } \\
\cline { 3 - 8 } & & \multicolumn{2}{c}{$9 .^{\circ}$ ano } & \multicolumn{2}{c}{$12 .^{\circ}$ ano } & \multicolumn{2}{c}{ Curso Superior } \\
\cline { 3 - 8 } & & Freq. & $\%$ & Freq. & $\%$ & Freq. & $\%$ \\
\hline \multirow{2}{*}{$7 .^{\circ}$} & masculino & 03 & 15,8 & 07 & 36,8 & 09 & 47,4 \\
\hline \multirow{2}{*}{$8 .^{\circ}$} & feminino & 13 & 48,1 & 10 & 37,0 & 04 & 14,8 \\
\hline \multirow{2}{*}{$9 .^{\circ}$} & masculino & 18 & 36,0 & 18 & 36,0 & 14 & 28,0 \\
\cline { 2 - 8 } & feminino & 07 & 20,6 & 21 & 61,8 & 06 & 17,6 \\
\hline & masculino & 10 & 23,3 & 20 & 46,5 & 13 & 30,2 \\
\hline
\end{tabular}

Língua Portuguesa apenas o fizeram os rapazes do $9 .^{\circ}$ ano de escolaridade.

Da análise da Tabela 2 poder-se-á inferir que as metas escolares pretendidas pelos alunos são idênticas, embora, no $7 .^{\circ}$ ano, os rapazes tenham aspirações superiores às raparigas. Contudo, da passagem do $8 .^{\circ}$ ano para o $9 .^{\circ}$ ano, ambos os sexos revelam um incremento nas suas aspirações escolares. Dos alunos da amostra, 54 (24,9\%) pretendem concluir apenas o $9 .^{\circ}$ ano de escolaridade, 94 $(43,3 \%)$ aspiram o $12 .^{\circ}$ ano e $69(31,8 \%)$ ambicionam concluir um curso superior.

\section{Instrumento}

Utilizamos a Ficha de Dados Pessoais e Escolares para avaliar o sexo, o ano de escolaridade, o número de reprovações, as horas de estudo, as metas escolares e as notas obtidas nas disciplinas de Língua Portuguesa e Matemática, variáveis incluídas no modelo de equações estruturais que hipotetizámos. Esta ficha foi apresentada aos alunos juntamente com o PHCSCS-2 e o APSA.

Foi introduzida uma pergunta directa na FDPE com a finalidade de obter o número de reprovações dos alunos ao longo do seu percurso escolar.

O tempo de estudo dos alunos foi analisado através de uma pergunta aberta relativa ao número de horas que dedicavam ao estudo numa semana.

Os alunos foram inquiridos sobre as suas ambições a nível académico através de uma questão, onde foram apresentadas 4 opções, nomeadamente: 1 - até ao $9 .^{\circ}$ ano de escolaridade;
2 - até ao $12 .^{\circ}$ ano de escolaridade; 3 - concluir um curso superior; 4 - ainda não decidi.

No sistema de educação básica em Portugal as notas apresentam a seguinte distribuição em todas as disciplinas: 1 e 2 (negativa); 3 (suficiente) até 5 (excelente). Nesta investigação foram consideradas as notas de Língua Portuguesa e Matemática pelo facto de os alunos estarem sujeitos a exame, no final deste ciclo, a estas disciplinas.

Para avaliar o autoconceito professado pelos alunos usou-se a Escala Piers-Harris Children's Self-Concept Scale-2, originalmente pensada e concebida por Piers (1984) e recentemente revista e publicada em versão reduzida por Piers e Hertzberg (2002). Para o presente trabalho foi aplicada a versão portuguesa adaptada e validada por Veiga (2006), sendo muito utilizada na avaliação do nível de autoconceito dos adolescentes. Assim, os indivíduos que alcançam as cotações mais altas na escala parecem ser os que apresentam um autoconceito mais elevado. A PHCSCS-2 é constituída por 60 itens distribuídos por 6 factores: aspecto comportamental (AC), estatuto intelectual (EI), aparência física (AF), ansiedade (AN), popularidade (PO) e satisfação-felicidade (SF). A escala apresenta alguns itens inversos e para a determinação da pontuação em cada item, é atribuído um ponto ou zero, conforme a resposta dada seja reveladora, respectivamente, de uma atitude positiva ou negativa face a si mesmo. Especificamente, no caso dos itens invertidos (e.g., "Os meus colegas de turma troçam de mim") a pontuação é 1 se a resposta for $n a \tilde{o} o$ e 0 se a resposta for sim.

Para avaliar o ambiente da sala de aula foi utilizada a Escala Ambiente Psicossociológico da Sala de Aula de Antunes (2002). Esta foi construída a partir de escalas adaptadas 
de dois instrumentos: da versão reduzida da CES de Fraser (1982, 1986) [a escala CES foi acrescentada por Freire e Veiga (1996)]; e da subescala Satisfação retirada do ILEQ (Knight \& Waxman, 1990). A APSA é constituída por 22 itens distribuídos por 5 factores: autoridade compreensiva do professor nas aulas (AC); envolvimento nas aulas (EA); afiliação nas aulas (AF); satisfação nas aulas (SA); e tarefas nas aulas (TA). Os itens foram medidos segundo uma escala de Likert de 6 pontos de (1) Discordo totalmente a (6) Concordo totalmente.

\section{Procedimentos de análise de dados}

Relativamente à recolha da informação, esta foi realizada na turma, durante o horário escolar, depois de obtidas as autorizações da direcção da escola e dos pais dos alunos. Os professores e os alunos foram informados dos objectivos da investigação, a sua participação foi voluntária e foi garantida a confidencialidade das respostas. $\mathrm{O}$ tratamento estatístico dos dados foi realizado com base no programa SPSS17/AMOS17 (Arbuckle, 2009; Lowe, Winzar \& Ward, 2007).

Analisados os resultados foram removidos todos os casos com missing values de forma a facilitar a estimação dos parâmetros utilizando o método da estimação maximum likelihood (ML) no programa AMOS. Optou-se, também, por manter os outliers, uma vez que a estatística descritiva de cada uma das amostras se mostrou ainda adequada.
O ajuste do modelo foi avaliado com base nos índices estatísticos mais habitualmente utilizados: Qui-quadrado $\left(\chi^{2}\right) ; \chi^{2}$ graus de liberdade; goodness-of-fit index (GFI), adjusted goodness-of-fit index (AGFI), comparative fit index (CFI) e root mean square error of aproximation (RMSEA). Num sentido mais restrito, o modelo hipotetizado não é significativamente diferente no contido na matriz dos dados empíricos quando o valor do $\chi^{2}$ tem uma probabilidade associada menor que .05 . Neste sentido, os investigadores desta área desenvolveram índices de ajuste complementares com os quais avaliam a plausibilidade de um dado modelo, entre os quais o GFI, AGFI, CFI e RMSEA. Os dois primeiros expressam a quantidade de variância/covariância explicada no modelo, estimando-se que valores iguais ou superiores a 0,90 são habitualmente avaliados como indicadores de ajustamento do modelo e indicam um ajuste aceitável, enquanto que os superiores a 0,95 referem um bom ajuste. $\mathrm{O}$ CFI é um índice que nos informa do ajuste do nosso modelo comparando-o com um modelo independente, considerando-se que valores iguais ou superiores a 0,95 são indicativos de um bom ajuste do modelo hipotetizado $(\mathrm{Hu} \&$ Bentler, 1999). Por sua vez, o índice RMSEA, introduzido por Browne e Cudeck (1993), é um indicador que aponta o erro de aproximação à população. Esta discrepância é expressa em graus de liberdade, o que torna este índice sensível ao número de parâmetros estimados (complexidade do modelo). Os valores que oscilam entre 0,08 e 0,06 indicam um ajuste razoável e quando são inferiores a 0,06 revelam um bom ajuste (Hu \& Bentler, 1999).

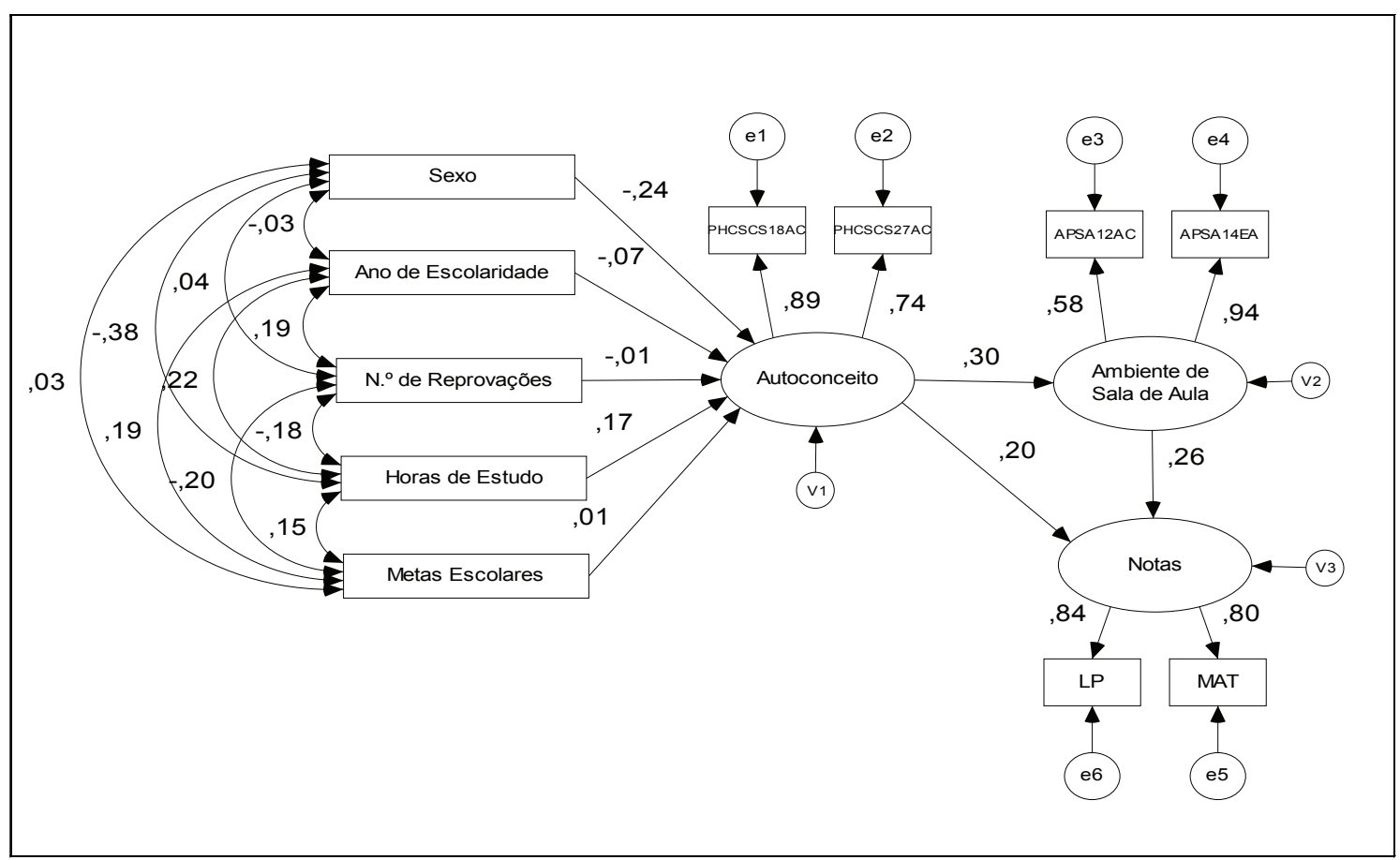

Legenda: Os itens PHCSCS seguidos das letras AC correspondem ao Aspecto Comportamental; o item APSA seguido das letras AC corresponde à Autoridade Compreensiva do professor na aula; O item APSA seguido das letras EA corresponde ao Envolvimento nas Aulas; V1=Variância residual da variável latente Autoconceito; V2=Variância residual da variável latente Ambiente Psicossociológico da Sala de Aula; V3=Variância residual da variável latente Notas finais do $2 .^{\circ}$ período; a letra (e) seguida de um número $(1,2, \ldots)$ diz respeito ao erro de medida da variável observável respectiva.

Figura 1. Especificação pictórica do modelo de relações causais com os valores estandardizados. 


\section{Resultados}

Após a recolha dos dados, fez-se a sua aplicação no modelo com alunos do $3 .^{\circ} \mathrm{CEB}$ (Figura 1), tendo como referência as disciplinas de Língua Portuguesa e Matemática, para definir o construto Notas. Relativamente ao construto Autoconceito, este é determinado pelos itens PHCSCS18AC e PHCSCS27AC e o construto Ambiente Psicossociológico da Sala de Aula, é definido pelos itens APSA12AC e APSA14EA.

No modelo assumimos que o autoconceito dos alunos influencia o ambiente psicossociológico da sala de aula (duas variáveis inferidas através dos escores obtidos a partir das respostas aos itens), bem como algumas variáveis exógenas (sexo, ano de escolaridade, número de reprovações, horas de estudo e metas escolares) também exercem influência no autoconceito dos alunos. Foi, igualmente, considerado que o autoconceito e o ambiente psicossociológico da sala de aula têm impacto no rendimento académico (notas a Língua Portuguesa e Matemática).

As relações causais que foram hipotetizadas neste modelo derivam directa ou indirectamente das referências explícitas na literatura (Fraser, 2002; Inglez de Souza \& Ferreira de Brito, 2008; Köller et al., 2000; Walker, 2004).

De seguida serão indicados alguns aspectos essenciais da estatística descritiva. Na Tabela 3 podem observar-se os dados descritivos (mínimos, máximos, média, desvio-padrão, assimetria e curtose) correspondentes às variáveis incluídas no modelo. Um dos pressupostos importantes nos modelos de equações estruturais é que a distribuição de qualquer variável seja normal com respeito a qualquer valor do resto das variáveis, o que implica que qualquer combinação linear das variáveis seja normal. Dado que o MLE pode desvirtuar os resultados quando este pressuposto é violado (West, Finch \& Curran, 1995), foi examinada a distribuição de cada uma das variáveis em termos da sua curtose e assimetria. Tomou-se como critério o estabelecido por Curran, West e Finch (1997), que consideram que valores de assimetria maiores que $3 \mathrm{e}$ de curtoses maiores do que 10 não devem ser considerados. $\mathrm{Na}$ amostra nenhuma variável revela valores próximos de tais critérios, pelo que se justifica proceder à estimação do ajuste do modelo mediante MLE.

A Figura 1 evidencia o modelo hipotetizado para os alunos da amostra. As relações causais possíveis são as constantes no modelo conforme as hipóteses delineadas no início da investigação.

Os índices de bondade de ajustamento global do modelo proposto são robustos $[\chi 2=54,5 ; \mathrm{gl}=31 ; \chi 2 / \mathrm{gl}=1,757$; GFI $=0,958$; AGFI $=0,911 ;$ CFI $=0,950$; RMSEA $=0,059(0,32-$ $0,085)]$, confirmando a hipótese de que o modelo proposto representa as relações entre as variáveis existentes na nossa matriz empírica.

Por outro lado, da análise da Tabela 4 e da Figura 1 pode inferir-se que as hipóteses que orientaram as especificações foram todas confirmadas:

H1. O sexo feminino revela um autoconceito inferior relativamente ao masculino $(\beta=-0,24 ; p<0,01)$ (Lourenço \& Paiva, 2010);

H2. Os alunos do $9 .^{\circ}$ ano de escolaridade apresentam um autoconceito inferior aos restantes anos de escolarida- $\operatorname{de}(\beta=-0,07 ; \mathrm{p}=0,386)$ (Entwistle, McCune \& Walker, 2000; Paiva, 2009);

H3. O autoconceito dos alunos é influenciado negativamente pelo número de reprovações $(\beta=-0,01$; $\mathrm{p}=0,921$ ) (Azevedo \& Faria, 2004; Paiva, 2009; Peixoto, 2004);

H4. Um maior investimento no tempo de estudo por parte dos alunos influencia positivamente o seu autoconceito $(\beta=0,17 ; p<0,05)$ (Formiga, 2004);

H5. As metas escolares definidas pelos alunos têm uma influência positiva no autoconceito dos mesmos ( $\beta=0,01 ; p=0,878$ ) (Köller et al., 2000; Paiva, 2009);

H6. O ambiente da sala de aula é afectado positivamente pelo autoconceito dos alunos $(\beta=0,30 ; p<0,01)$ (Elbaum \& Vaughn, 2001; Paiva \& Lourenço, 2010);

H7. O autoconceito dos alunos influi positivamente nas suas notas escolares $(\beta=0,20 ; p<0,05)$ (Inglez de Souza \& Ferreira de Brito, 2008; Lourenço \& Paiva, 2010; Paiva, 2009);.

H8. O ambiente da sala de aula tem um impacto positivo no rendimento académico dos alunos $(\beta=0,26$; $\mathrm{p}<0,01$ ) (Lourenço, 2009; Paiva \& Lourenço, no prelo);

Da análise dos resultados, é de realçar que a maioria dos valores de regressão de uma variável sobre a outra são significativos. Quanto às variáveis exógenas, da análise da Tabela 4 , poder-se-á ainda referir que à medida que se progride na escolaridade os alunos reprovam mais $(\beta=0,19)$, contudo apresentam um maior investimento do tempo de estudo $(\beta=0,22)$ e metas escolares mais elevadas $(\beta=0,19)$. Constata-se, também, que os alunos que apresentam um maior número de reprovações são os que investem menos tempo no seu estudo $(\beta=-0,18)$, bem como apresentam metas escolares menos ambiciosas $(\beta=-0,20)$. Nesta sequência, os alunos que investem mais no estudo apresentam metas escolares mais elevadas $(\beta=0,15)$. Os alunos do sexo feminino estudam menos $(\beta=-0,38)$, reprovam mais $(\beta=0,04)$, mas têm metas escolares mais ambiciosas $(\beta=0,03)$. De salientar que todas estas relações são estatisticamente significativas, à excepção das relações entre o sexo e as metas escolares e entre o sexo e o número de reprovações.

\section{Discussão}

Os estudos desenvolvidos tendo como objectivo a procura das relações entre o autoconceito e o desempenho académico, têm sofrido um incremento ao longo dos anos e os resultados dessas investigações apontam para uma persistente e significativa relação entre as duas variáveis (Inglez de Souza \& Ferreira de Brito, 2008; Köller et al., 2000; Marsh et al., 1998; Mui, Yeung, Low \& Jin, 2000; Paiva, 2009). Os investigadores partem do pressuposto que as percepções negativas dos 
Tabela 3. Estatística descritiva (mínimo, máximo, média, desvio-padrão, assimetria e curtose) correspondente às variáveis incluídas no modelo de equações estruturais

\begin{tabular}{lcccccc}
\hline Variável & Mínimo & Máximo & Média & DP & Assimetria & Curtose \\
\hline N. ${ }^{\circ}$ de Reprovações & 0 & 5 & 1,59 & 1,29 & 0,524 & $-0,424$ \\
Horas de Estudo & 0 & 9 & 2,40 & 2,49 & 1,064 & 0,184 \\
Língua Portuguesa & 1 & 5 & 2,82 & 0,78 & 0,092 & $-0,310$ \\
Matemática & 1 & 5 & 2,65 & 0,96 & 0,422 & $-0,250$ \\
PHCSCS18AC & 0 & 1 & 0,59 & 0,49 & $-0,365$ & $-1,866$ \\
PHCSCS27AC & 0 & 1 & 0,60 & 0,49 & $-0,404$ & $-1,837$ \\
APSA12AC & 1 & 6 & 4,24 & 1,59 & $-0,670$ & $-0,562$ \\
APSA14EA & 1 & 6 & 3,90 & 1,52 & $-0,366$ & $-0,708$ \\
\hline
\end{tabular}

Legenda: Os itens PHCSCS seguidos das letras AC correspondem ao Aspecto Comportamental; o item APSA seguido das letras AC corresponde à Autoridade Compreensiva do professor na aula; o item APSA seguido das letras EA corresponde ao Envolvimento nas Aulas.

Tabela 4. Resultados da contrastação da estrutura de covariância (valor e erro estimado e nível de significância) hipotetizado para a amostra

\begin{tabular}{|c|c|c|c|c|c|}
\hline Hipóteses & & $\begin{array}{l}\text { Valores não } \\
\text { estandardizados }\end{array}$ & $\begin{array}{c}\text { Valores estandar- } \\
\text { dizados }\end{array}$ & Erro de estimativa & $p$ \\
\hline $\mathrm{H} 1$ & Sexo $\rightarrow$ Autoconceito & $-0,206$ & $-0,24$ & 0,068 & 0,002 \\
\hline $\mathrm{H} 2$ & Ano de escolaridade $\rightarrow$ Autoconceito & $-0,038$ & $-0,07$ & 0,044 & 0,386 \\
\hline $\mathrm{H} 3$ & N. ${ }^{\text {de }}$ Reprovações $\rightarrow$ Autoconceito & $-0,003$ & $-0,01$ & 0,026 & 0,921 \\
\hline $\mathrm{H} 4$ & Horas de estudo $\rightarrow$ Autoconceito & 0,030 & 0,17 & 0,014 & 0,035 \\
\hline H5 & Metas Escolares $\rightarrow$ Autoconceito & 0,007 & 0,01 & 0,044 & 0,878 \\
\hline H6 & Autoconceito $\rightarrow$ Ambiente de sala de aula & 0,637 & 0,30 & 0,239 & 0,008 \\
\hline $\mathrm{H} 7$ & Autoconceito $\rightarrow$ Notas & 0,343 & 0,20 & 0,161 & 0,033 \\
\hline \multirow[t]{17}{*}{$\mathrm{H} 8$} & Ambiente de sala de aula $\rightarrow$ Notas & 0,222 & 0,26 & 0,076 & 0,004 \\
\hline & Sexo $\leftrightarrow$ Ano de Escolaridade & $-0,013$ & $-0,03$ & 0,026 & 0,613 \\
\hline & Sexo $\leftrightarrow$ N. $^{\text {o }}$ de Reprovações & 0,028 & 0,04 & 0,044 & 0,524 \\
\hline & Sexo $\leftrightarrow$ Horas de Estudo & $-0,470$ & $-0,38$ & 0,090 & 0,000 \\
\hline & Sexo $\leftrightarrow$ Metas Escolares & 0,013 & 0,03 & 0,026 & 0,620 \\
\hline & Ano de Escolaridade $\leftrightarrow N^{\circ}{ }^{\circ}$ de Reprovações & 0,183 & 0,19 & 0,068 & 0,007 \\
\hline & Ano de Escolaridade $\leftrightarrow$ Horas de Estudo & 0,408 & 0,22 & 0,132 & 0,002 \\
\hline & Ano de Escolaridade $\leftrightarrow$ Metas Escolares & 0,107 & 0,19 & 0,039 & 0,007 \\
\hline & N. ${ }^{o}$ de Reprovações $\leftrightarrow$ Horas de Estudo & $-0,582$ & $-0,18$ & 0,222 & 0,009 \\
\hline & 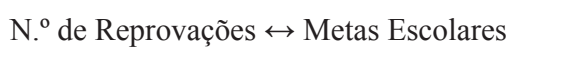 & $-0,197$ & $-0,20$ & 0,067 & 0,003 \\
\hline & Horas de Estudo $\leftrightarrow$ Metas Escolares & 0,286 & 0,15 & 0,128 & 0,026 \\
\hline & Autoconceito $\rightarrow$ PHCSCS18AC & 1,000 & 0,89 & - & - \\
\hline & Autoconceito $\rightarrow$ PHCSCS27AC & 0,831 & 0,74 & 0,130 & 0,000 \\
\hline & Ambiente de sala de aula $\rightarrow$ APSA12AC & 1,000 & 0,58 & - & - \\
\hline & Ambiente de sala de aula $\rightarrow$ APSA14EA & 1,553 & 0,94 & 0,426 & 0,000 \\
\hline & Notas $\rightarrow$ LP & 0,852 & 0,84 & 0,163 & 0,000 \\
\hline & Notas $\rightarrow$ Mat & 1,000 & 0,80 & - & - \\
\hline
\end{tabular}

Legenda: LP=Língua Portuguesa; Mat=Matemática; Os itens PHCSCS seguidos das letras AC correspondem ao Aspecto Comportamental; o item APSA seguido das letras AC corresponde à Autoridade Compreensiva do professor na aula; o item APSA seguido das letras EA corresponde ao Envolvimento nas Aulas. 
sujeitos acerca deles próprios constituem um factor-chave do insucesso escolar. Por exemplo, muitos alunos terão dificuldades e insucesso na Matemática não por falta de inteligência ou de outras capacidades, mas porque se percepcionam como incapazes de aprender ou fazer bem as coisas. A origem desta auto-avaliação negativa está muitas vezes no feedback que recebem através de repreensões verbais persistentes e de classificações escolares negativas (Veiga, 2001).

Outros estudos apontam nesse mesmo sentido, sublinhando que o fracasso em determinadas tarefas pode não apenas baixar o autoconceito de capacidades nessas tarefas específicas, como ainda gerar um efeito de onda em relação a outras tarefas (Neto, 2004). Com uma amostra de 113 sujeitos de 10 anos de idade, Gordon (1977) avaliou o autoconceito com a PHCSCS e o rendimento com as notas dos alunos, tendo encontrado as correlações: $\mathrm{r}=0,14(\mathrm{p}=\mathrm{n} . \mathrm{s}$.) com a Matemática; e $\mathrm{r}=0,25(\mathrm{p}<0,01)$ com a Língua Materna.

Segundo Rodrigues (1984), tal problema só poderá ser solucionado se o profissional responsável observar as disposições subjacentes ao comportamento dos alunos e professores, da maneira mais fiel possível, ou seja, mantendo uma certa neutralidade quanto às rotulações ou atribuições preconceituosas (e.g., diferenciação quanto ao sexo, classe). Tais comportamentos podem trazer como consequência, entre outras, a maior quantidade de inputs que alguns professores podem dar aos alunos considerados com um melhor desempenho escolar, isto é, há um maior reforço do professor para os estudantes considerados mais capazes, mesmo que não intencionalmente. Factos como estes elucidam a necessidade de se ter para com o aluno uma visão holística do seu $E u$ aprendiz, pois o fracasso escolar do aluno denuncia uma idiossincrasia entre o seu Self e as suas experiências, e essas, muitas vezes, são desconsideradas pelo ambiente escolar.

A promoção de ambientes que os alunos entendam como capazes de induzir uma abordagem profunda e em que possam efectuar aprendizagens significativas, constitui o desafio sugerido ao sistema educativo em geral e aos professores em particular (Paiva, 2008). A literatura destaca a influência da percepção dos alunos sobre os métodos de ensino e de avaliação usados pelos docentes e das matérias que integram o currículo na adopção de uma determinada abordagem à aprendizagem. Ramsden (1988) referiu que os alunos nunca recebem, de forma passiva, a instrução do professor. Adaptam-se ao contexto, tentando corresponder ao que o docente manifesta valorizar na aprendizagem.

Nesta sequência, e como realçam Martini e Boruchovitch (2004), é imprescindível pesquisar como os alunos, que simultaneamente com os professores, estabelecem o núcleo e a base do processo ensino/aprendizagem, interpretam e vivenciam as suas experiências de sucesso e fracasso escolar. Como as atribuições de causalidade são susceptíveis de serem alteradas, esse conhecimento pode facultar contributos essenciais para a análise das condições objectivas de produção de crenças desajustadas, para a concretização de esforços de forma a alterar essas crenças, bem como para criar contextos mais favoráveis ao sucesso académico, à motivação e à afectividade dos alunos (Martini \& Del Prette, 2002).

Elbaum e Vaughn (2001) descreveram que os estudos para melhorar o autoconceito dos alunos podem ser potencializados por uma participação mais envolvente por parte dos pais, particularmente com os adolescentes com dificuldades de aprendizagem, de forma a apoiar o empenho escolar e fomentar a integração social dos alunos na comunidade educativa. A acrescentar ao ambiente familiar poder-se-á introduzir o ambiente da sala de aula, através dos professores e pares, na formação e modulação do autoconceito dos jovens na fase escolar.

Um estudo elaborado por Taliuli (1982, conforme citado por Roldão, 2003) sobre a relação entre o rendimento académico e o autoconceito de alunos com sucesso e de alunos com insucesso escolar, veio demonstrar, sistematicamente, que os alunos com melhor desempenho obtiveram resultados de autoconceito significativamente mais altos, do que os com desempenho insatisfatório.

É indispensável, ainda, abordar a problemática do rendimento escolar, realçando a influência bidireccional dos aspectos psicossociais e de socialização. $\mathrm{O}$ (in)sucesso escolar, na medida em que está relacionado com o autoconceito do indivíduo, pode reflectir-se nos mais variados aspectos da sua vida, como na escolha profissional, na motivação para o estudo, entre outros (House, 2000; Okano \& Loureiro, 2008; Paiva, 2009). Especificamente no domínio académico, as pesquisas revelam que uma melhoria no autoconceito poderá levar a uma melhoria no rendimento escolar. $\mathrm{O}$ autoconceito e o rendimento escolar parecem, por isso, apresentar uma relação positiva.

Determinadas pesquisas revelam como o rendimento em sala de aula pode sofrer impacto do tipo de relação que o professor estabelece com os seus alunos. Algumas qualidades do professor ou características de personalidade como paciência, dedicação, vontade de ajudar e atitude democrática promovem a aprendizagem (Chalita, 2001). Contrariamente, o autoritarismo e a inimizade originam antipatia por parte dos alunos, fazendo com que estes associem a matéria ao professor e respondam de uma forma negativa a ambos (Cook et al., 2008). Deste modo, Santeiro, Santeiro e Andrade (2004) referem que é de extrema relevância o papel do professor no desenvolvimento do potencial criativo de seus alunos. Assim, poder-se-á pensar que na sala de aula podem ocorrer constantes "intercâmbios criativos", optimizando a qualidade das relações aí estabelecidas. Professores com um espírito criativo induzem nos alunos essa criatividade.

Relativamente às correlações múltiplas quadradas obtidas no modelo especificado, os seus valores indicam-nos que o autoconceito dos alunos está explicado em 14\%, directamente pelas variáveis exógenas sexo, ano de escolaridade, número de reprovações, horas de estudo e metas escolares. Por seu lado, a variável ambiente psicossociológico da sala de aula está explicada directamente pelo autoconceito em 9,2\%, o que nos levará a pensar que os alunos cujo autoconceito é mais elevado têm uma percepção mais positiva do ambiente de sala de aula. No que diz respeito à variável notas esta é explicada em $11,5 \%$, também directamente pelas variáveis autoconceito e ambiente da sala de aula. Estes valores estão em consonância com os obtidos noutros estudos (Lourenço \& Paiva, 2010; Paiva, 2009; Paiva \& Lourenço, no prelo). Deste modo, as três variáveis endógenas que integram o modelo (variáveis dependentes mediadoras) não se encontram igualmente explicadas pelos efeitos estimados no modelo. O conjunto de relações causais especificadas apresenta um baixo nível explicativo relativamente a alguns construtos em estudo. Estes resultados, não comprometendo a validade do 
modelo que ajustou de uma forma muito satisfatória, representam, no entanto, uma importante limitação quanto à capacidade explicativa dos efeitos entre as variáveis. Contudo, as possíveis variações nas mesmas parecem estar determinadas também por outras variáveis não incluídas no modelo.

Estes dados, incontornáveis, sugerem a necessidade de reespecificarmos o modelo, procurando outras variáveis que, influindo significativamente nas variáveis dependentes, aumentem a variância explicada das variáveis endógenas. Tal como referem Guay, Marsh e Boivin (2003), seria também importante estudar o autoconceito em vários domínios, de forma a avaliar os processos subjacentes à formação do próprio autoconceito nesses mesmos domínios e a sua relação com o rendimento académico e outros construtos. Nesta sequência poder-se-á considerar, também, a necessidade de se realizarem mais estudos para se compreenderem os processos psicológicos e as práticas de sala de aula que medeiam a relação entre o autoconceito e o rendimento académico.

Por último, esta investigação, com um carácter essencialmente exploratório, e sem pretensão de generalização, é, contudo, vasta em sugestões para investigações que arrisquem novos territórios com vista ao sucesso académico. Não se pretende responder totalmente ao problema em questão, quer pelos limites de algumas variáveis em estudo, quer pela necessidade de replicar esta pesquisa, tendo em consideração outras amostras sociodemográficas com características diferenciadas. Porém, o que se procurou foi construir um modelo onde fosse possível reflectir sobre a relação existente entre o autoconceito, o ambiente psicossociológico da sala de aula, o rendimento académico e algumas variáveis sociodemográficas, partindo, essencialmente, das vivências quotidianas do aluno no espaço escolar e da sua dinâmica atitudinal perante o sucesso académico, considerando-o como um ser dinâmico e, simultaneamente, mestre e aprendiz.

\section{Referências}

Antunes, J. (2002). Motivação e atitudes dos jovens alunos face ao ambiente da aula e da escola. Dissertação de Mestrado, Universidade de Lisboa, Lisboa.

Arbuckle, J. L. (2009). Amos 18.0 User's Guide. Crawfordville: Amos Development Corporation.

Azevedo, A., \& Faria, L. (2004). Manifestações diferenciais do auto-conceito no fim do ensino secundário português. Paidéia, 14, 265-276.

Bandura, A. (1986). Social foundations of thought and action: a social cognitive theory. Englewood Cliffs, N. J.: Prentice-Hall.

Browne, M. W., \& Cudeck, R. (1993). Alternative ways of assessing model fit. In K. A. Bollen \& J. S. Long (Eds.), Testing Structural Equation Models (pp. 445-455). Newbury Park, CA: Sage.

Burns, R. B. (1979). The self-concept. London: Longman.

Byrne, B. M. (1986). Self-concept: academic achievement relations. An investigation of dimensionality, stability and causality. Canadian Journal of Behavioral Science, 18(2), 173-186.

Chalita, G. (2001). Educação: a solução está no afeto. SP: Gene.

Cirino, S. D., Eiterer, C. L., \& Guimarães, E. J. (2004). Laboratório de Produção de Material Didático - PROMAD. Trabalho apresentado em Anais do XII Encontro Nacional de Didática e Prática de Ensino (pp. 7887-7896), Curitiba.
Cook, C. R., Gresham, F. M., Kern, L., Barreras, R. B., Thornton, S., \& Crews, S. D. (2008). Social skills training for secondary students with emotional and/or behavioral disorders-A review and analysis of the meta-analytic literature. Journal of Emotional and Behavioral Disorders, 16(3), 131-144.

Curran, P. J., West, S. G., \& Finch, J. F. (1997). The robustness of test statistics to non-normality and specification error in confirmatory factor analysis. Psychological Methods, 1, 16-29.

Edinger, M. (2000). Competition versus cooperation and pupil achievement. College Student Journal, 34(1), 14-22.

Elbaum, B., \& Vaughn, S. (2001). School-based interventions to enhance the self-concept of students with learning disabilities: a meta-analysis. The Elementary School Journal, 10(3), 303-329.

Entwistle, N. J., McCune, V. \& Walker, P. (2000). Conceptions, styles and approaches within higher education: analytic abstractions and everyday experience. In R. J. Sternberg \& L-F. Zang (Eds.), Perspectives on Cognitive, Learning and Thinking Styles (pp. 211-245). Mahwah, N. J.: Lawrence Erlbaum.

Formiga, N. S. (2004). O tipo de orientação cultural e sua influência sobre os indicadores do rendimento escolar. Psicologia: Teoria e Prática, 6(1), 13-29.

Fraser, B. (1982). Development of several classroom environment scales. Journal of Educational Measurement, 19, 221-227.

Fraser, B. (1986). Classroom environment. London: Croom Helm.

Fraser, B. J. (2002). Learning environments research: yesterday, today and tomorrow. In S. C. Goh \& M. S. Khine (Eds.), Studies in educational learning environments: An international perspective (pp. 1-25). River Edge, NJ: World Scientific.

Freire, M. V., \& Veiga, F. H. (1996). Versão do "Classroom Environment Scale" (CES), para a disciplina de ciências. In M. V. Freire (Ed.), Desempenho a Ciências: Análise em Função do Ambiente de Aula, do Autoconceito e do Locus de Controlo (pp. 35-46). Lisboa: Departamento de Educação da FCUL.

Giavoni, A., \& Tamayo, A. (2003). Inventário masculino dos esquemas de gênero do autoconceito (IMEGA). Psicologia: Teoria e Pesquisa, 19(3), 249-259.

Gordon, D. A. (1977). Children's beliefs in internal external control and self-esteem as related to academic achievement. Journal of Personality Assessment, 41, 383-386.

Guay, F., Marsh, H. W., \& Boivin, M. (2003). Academic SelfConcept and Academic Achievement: Developmental Perspectives on Their Causal Ordering. Journal of Educational Psychology, 95(1), 124-136.

House, J. D. (2000). The effects of student involvement on the development of academic self-concept. Journal of Social Psychology, 140, 261-263.

Hu, L.-T., \& Bentler, P. M. (1999). Cut off criteria for fit indexes in covariance structure analysis: conventional criteria versus new alternatives. Structural Equation Modeling: A Multidisciplinary Journal, 6, 1-55.

Huertas, J. A. (2000). La gramatica de los motivos en la aula. Educação, 23(41), 131-146.

Inglez de Souza, L. \& Ferreira de Brito, M. (2008). Crenças de auto-eficácia, autoconceito e desempenho em matemática. Estudos de Psicologia, 25(2), 193-201.

Knight, S. L., \& Waxman, H. C. (1990). Investigating the effects of the classroom learning environment on student's motivation in social studies. Journal of Social Studies Research, 14(1), 15-34. 
Köller, O., Daniels, Z., Schnabel, K. U., \& Baumert, J. (2000). Kurswahlen von Maedchen und Jungen im Fach Mathematik: Zur Rolle von fachspezifischem Selbstkonzept und Interesse. [Course selections of girls and boys in mathematics: The role of academic self-concept and interest.]. Zeitschrift für Pädagogische Psychologie, 14, 26-37.

Leitão, F. C. T. (2008). Diferenciação e desenvolvimento do autoconceito em alunos do $3 .^{\circ}$ ciclo do ensino básico e do ensino secundário. Dissertação de Mestrado, Universidade do Porto, Porto.

Liparini, A., \& Munford, D. (2005). Análise de discurso dentro da sala de aula e a influência da metodologia tempestade de ideias no processo de aprendizagem dos alunos. Trabalho apresentado no Anais do I Encontro Nacional de Ensino de Biologia (pp. 602-606), Rio de Janeiro.

Lourenço, A. A. (2009). Disrupção Escolar no 3. ${ }^{\circ}$ ciclo do Ensino Básico: Influência do Ambiente Psicossociológico da Sala de Aula. Trabalho de Pós-doutoramento, Escola de Estudos Pós-Graduados e de Investigação da Universidade Fernando Pessoa, Porto.

Lourenço, A. A., \& Paiva, M. O. A. (2004). Disrupção Escolar Estudo de casos. Porto: Porto Editora.

Lourenço, A. A., \& Paiva, M. O. A. (2010). Autoconceito e rendimento académico: um estudo com modelos de equações estruturais. Revista Galego-Portuguesa de Psicoloxía e Educación, 18(1), 177-194.

Lowe, B., Winzar, H., \& Ward, S. (2007). Essentials of SPSS for Windows versions $14 \&$ 15: a business approach. South Melbourne, Victoria: Thomson Learning Australia.

Marsh, H. W., \& Craven, R. (1997). Academic self-concept: Beyond the dustbowl. In G. Phye (Ed.), Handbook of classroom assessment: Learning, achievement, and adjustment (pp. 131198). Orlando, FL: Academic Press.

Marsh, H. W., Craven, R. G., \& Debus, R. (1998). Structure, stability, and development of young children's self-concepts: A multicohort-multioccasion study. Child Development, 69, 1030-1053.

Martini, M. L., \& Boruchovitch, E. (2004). A teoria da atribuição de causalidade: Contribuições para a formação e atuação de educadores. Campinas: Alínea.

Martini, M. L., \& Del Prette, Z. (2002). Atribuições de causalidade de professoras do ensino fundamental para o sucesso e o fracasso escolar dos seus alunos. Revista Interação em Psicologia, 6(2), 49-156.

Mui, F. L. L., Yeung, A. S., Low, R., \& Jin, P. (2000). Academic selfconcept of talented students: Factor structure and applicability of the internal/external frame of reference model. Journal for Education of the Gifted, 23(3), 343-367.

Neto, F. (2004). Psicologia Social Aplicada (Vol. II). Lisboa: Universidade Aberta.

Oldfather, P., \& McLaughlin, H. J. (1993). Gaining and losing voice: A longitudinal study of students' continuing impulse to learn across elementary and middle level contexts. Research in Middle Level Education Quarterly, 3, 1-25.

Okano, C. B., \& Loureiro, S. R. (2008). Suporte psicopedagógico na escola: estudo de seguimento com escolares. Psicologia: Teoria e Pesquisa, 24(3), 287-294.

Paiva, M. O. A. (2004). Influência dos factores sócio-culturais e da estrutura familiar no desenvolvimento da personalidade dos adolescentes. Revista de Psiquiatria e de Psicologia, 25(1-2-3-4), 9-28.
Paiva, M. O. A. (2008). Abordagens à aprendizagem e abordagens ao ensino:Uma aproximação à dinâmica do aprender no Secundário. Dissertação de Doutorado, Universidade do Minho, Braga.

Paiva, M. O. A. (2009). A dinâmica do autoconceito na disrupção escolar: um estudo com alunos do $3 .^{\circ}$ ciclo do ensino básico. Trabalho de Pós-doutorado, Escola de Estudos Pós-Graduados e de Investigação da Universidade Fernando Pessoa, Porto.

Paiva, M. O. A., \& Lourenço, A. A. (2010). Comportamentos disruptivos e sucesso académico: a importância de variáveis psicológicas e de ambiente. Revista Argentina de Ciencias del Comportamiento, 2(2), 18-31.

Paiva, M. O. A., \& Lourenço, A. A. (no prelo). Ambiente da sala de aula: Um estudo de caso. Educação \& Filosofia, 25(49).

Parker, A. K. (2009). Elementary Organizational Structures and Young Adolescents' Self-Concept and Classroom Environment Perceptions Across the Transition to Middle School. Journal of Research in Childhood Education, 23(3), 325-339.

Peixoto, F (2004). Qualidade das relações familiares, auto-estima, auto-conceito e rendimento académico. Análise Psicológica, $22,235-244$.

Piers, E. V. (1984). Manual for the Piers-Harris Children's SelfConcept Scale (The Way I Feel About Myself) (2 $2^{\mathrm{a}}$ ed. rev.). Tennesse: Counselor Recording and Tests.

Piers, E. V., \& Herzberg, D. S. (2002). Piers-Harris 2: Piers-Harris Children's Self-Concept Scale (2 ${ }^{\mathrm{a}}$ ed. rev.). Wilshire Boulevard, California: Western Psychological Services.

Ramsden, P. (1988). Context and strategy: situational influences on learning. In R. R. Schmeck (Ed.), Learning strategies and learning styles (pp. 150-184). NY: Plenum Press.

Rodrigues, A. (1984). Aplicações da psicologia social. Petrópolis: Vozes.

Roldão, D. (2003). Motivação e auto-conceito em alunos do $1 .^{\circ} \mathrm{e}$ 2. ${ }^{\circ}$ ciclo do ensino básico. Monografia, Universidade Lusófona de Humanidades e Tecnologias, Lisboa.

Santeiro, T. V., Santeiro, F. R. M., \& Andrade, I. R. (2004). Professor facilitador e inibidor da criatividade segundo universitários. Psicologia em Estudo, 9(1), 95-102.

Simões, M. F. (2001). O interesse do auto-conceito em educação ( $1^{\mathrm{a}}$ ed.). Lisboa: Plátano Edições Técnicas.

Veiga, F. H. (2001). Indisciplina e violência na escola: Práticas comunicacionais para professores e pais ( $2^{\mathrm{a}} \mathrm{ed}$.). Coimbra: Almedina.

Veiga, F. H. (2006). Uma nova versão da escala de autoconceito: Piers-Harris Children's Self-Concept Scale (PHCSCS-2). Revista Psicologia e Educação, 5(2), 39-48.

Walker, S. L. (2004). Learning environment research: A review of the literature. Learning Environments Monograph No. 3, Texas State University, San Marcos.

West, S. G., Finch, J. F., \& Curran, P. J. (1995). Structural equation models with non-normal variables: Problems and remedies. Em R. Hoyle (Org.), Structural equation modelling: Concepts issues and applications, (pp. 56-75). Newbury Park, CA: Sage.

Recebido em 15.07.2009

Primeira decisão editorial em 10.03.2011

Versão final em 17.06.2011

Aceito em 18.06.2011 